\title{
Orofacial myofunctional changes and electromyographic activity of the orbicularis oris muscle in trombonists
}

\author{
Ana Paula Arruda de Moura ${ }^{1}$ \\ https://orcid.org/0000-0002-0109-047X \\ Jully Anne Soares de Lima \\ https://orcid.org/0000-0001-9724-1895 \\ Eduarda de Lima Amarante ${ }^{1}$ \\ https://orcid.org/0000-0001-9980-863X \\ Larissa Nadjara Alves Almeida ${ }^{2}$ \\ https://orcid.org/0000-0002-6818-3398 \\ Luciane Spinelli de Figueirêdo Pessoa² \\ https://orcid.org/0000-0003-3518-5060 \\ Leandro de Araújo Pernambuco ${ }^{2}$ \\ https://orcid.org/0000-0001-6246-9769 \\ Giorvan Ânderson dos Santos Alves ${ }^{2}$ \\ https://orcid.org/0000-0003-1619-0139
}

Universidade Federal da Paraíba - UFPB, João Pessoa, Paraíba, Brasil.

Universidade Federal da Parába - UFPB, Departamento de Fonoaudiologia, João Pessoa, Paraíba, Brasil.

Conflict of interests: Nonexistent

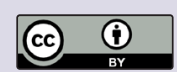

Received on: April 30, 2020

Accepted on: October 5, 2020

Corresponding address:

Giorvan Ânderson dos Santos Alves

Rua Dr. Ivanildo Guedes Pessoa, № 184,

Apto 901, Jardim Oceania

CEP: 58037-325 - João Pessoa, Paraíba Brasil

E-mail: anderson_ufpb@yahoo.com.br

\section{ABSTRACT}

Objective: to analyze whether trombonists present orofacial myofunctional changes and compare the electrical activity of the orbicularis oris muscle before and after playing their instrument.

Methods: an observational, descriptive, and cross-sectional study. The sample consisted of 20 university trombonists. Data collection involved three steps: application of a questionnaire investigating some peculiarities of trombonists (Orofacial Myofunctional Evaluation with Expanded Scores - OMES-E), and electromyographic analysis of the orbicularis oris muscle before and after performing a piece with the trombone. The mean, standard deviation, frequency, and percentage were calculated, and the paired Student's t test was used to compare the means of the electromyographic records before and after playing the trombone, at a $5 \%$ significance.

Results: seventy per cent of trombonists reported some symptom of orofacial myofunctional alteration, namely, muscle compensations, tension, and pain. The myofunctional evaluation showed a mild change in cheek volume $(90 \%)$ and labial commissure asymmetry $(60 \%)$. The electrical activity of the lower orbicularis oris muscle decreased significantly after the trombone practice $(p=0.04)$, while that of the superior orbicularis oris muscle remained unchanged.

Conclusion: trombonists show clinical and self-reported oromyofunctional changes as well as decreased electrical activity of the lower orbicularis oris muscle, after playing the trombone.

Keywords: Stomatognathic System; Musicians; Electromyography; Facial Muscles 


\section{INTRODUCTION}

The orbicularis oris muscles are complex and have intrinsic and extrinsic fibers that innervate the lips, which are the most mobile structures of the face ${ }^{1,2}$.

Any change in stomatognathic structures and functions can disrupt the entire stomatognathic system $(\mathrm{SS})^{1,3}$. This includes affecting muscle electrical activity, which is triggered by the excitation of muscle fibers by nerve ones. Details of the activity can be captured by surface electromyography (sEMG) ${ }^{2}$.

One of the factors that can unbalance $S S$ is excessive or inadequate use of the structures and functions of this system. The constant use of musical instruments, especially wind instruments, is one of the causes of orofacial complications. Thus, wind musicians are exposed to work-related risk factors ${ }^{4}$.

Playing a musical instrument is seen as something pleasant and harmonious, and the real effort behind a beautiful performance is hardly noticeable. The perfect melody is more and more sought after, requiring coordination, flexibility, aptitude, and fine motor skills. To achieve success in their professional lives, many instrumentalists go beyond their capacity of concentration, speed, precision, and resistance, which can trigger disorders in the orofacial complex ${ }^{5-8}$.

In recent years, health professionals have sought more information about how musical instruments act on the human body ${ }^{9}$. Some authors highlight the importance of orofacial myofunctional assessment, and define strategies for its application ${ }^{10-13}$. Despite the recognized importance of clinical evaluation, it has limitations related to subjectivity ${ }^{14,15}$. In this perspective, sEMG is a complementary quantitative test that determines muscle activity. This tool enables clinical investigation of muscular electrical activity, checking the physiology of individuals ${ }^{16-18}$.

In the case of trombonists, the constant use of the orbicularis oris muscle is notorious. This muscle consists of intrinsic and extrinsic fibers that innervate the upper and lower lips, which are the most mobile structures of the face $e^{1,2}$.

Considering the small number of studies on orofacial motricity with this target population, the present study analyzes whether there are clinical and self-reported myofunctional orofacial changes in trombonists, and compares the electrical activity of the orbicularis oris muscle before and after playing the trombone.

The study was guided by the following questions: What are the characteristics of the stomatognathic structures of trombonists, and how do these individuals perform stomatognathic functions? Does the use of trombone significantly affect the electromyographic records of the orbicularis oris muscle? Is there a perception on the part of these musicians in relation to these characteristics and functions, especially in the presence of changes?

The study considered the following hypotheses: myofunctional orofacial changes are present in trombonists; these musicians perceive the presence of changes; the use of trombone interferes with the electromyographic records of the orbicularis oris muscle.

\section{METHODS}

This research was approved by the Human Research Ethics Committee of the Health Sciences Center of the Federal University of Paraíba, PB, Brazil, under protocol number 1.826.161. The research follows the guidelines of Resolution No. 466/2012 of the National Health Council (CNS).

This is an observational, descriptive, and crosssectional study ${ }^{19}$. The nonprobabilistic sample consisted of 20 young male adults aged between 18 and 30 years. Participants were selected by convenience sampling from a population of college trombonists. All subjects agreed to voluntarily participate in the study by signing the Free and Informed Consent Form after receiving information about all the study procedures.

The study included young music undergraduates from a public university, duly enrolled in trombone classes 1 to 8 . Female subjects were excluded from the sample due to muscle physiology.

The subjects who agreed to voluntarily participate in the study were asked to answer a questionnaire (ANNEX A) prepared by the researchers themselves, which addressed their musical trajectory and selfreport of signs and symptoms of orofacial myofunctional changes related to the use of the instrument. Afterwards, the subjects were submitted to Orofacial Myofunctional Assessment with the application of the OMES-E protocol. This is a specific and comprehensive tool in Orofacial Motricity, whose expanded scores allow for graduation of specific orofacial myofunctional disorders ${ }^{15}$.

The first part of the protocol consists of collecting personal data of the patient. Evaluation begins with the appearance and posture; face; mandible/maxilla ratio; lips; mentual muscle (chin); tongue; hard palate; and mobility of these structures. It then evaluates breathing, swallowing, and chewing functions. Finally, 
it investigates other behaviors and signs of change. Application of the OMES-E protocol included the use of procedure gloves, French bread, and a digital camera (model Cyber-shot DSC-W310, Sony Corporation, Tokyo, Japan) for image recording.

After orofacial myofunctional assessment with the OMES-E protocol, the volunteers were submitted to electromyographic assessment of the orbicularis oris muscle in the upper and lower lips. For that, a 4-channel electromyograph (brand MIOTEC ${ }^{\circledR}$, model Miotool 200/400 USB) was used, connected by cables to a portable computer and working together with the Miograph software. Only two channels were used, referring to the regions of interest of the orbicularis oris muscle; the other channels were disabled ${ }^{16}$. This step included the use of procedure gloves, disposable disc-like bipolar surface capture electrodes, gauze, and $70 \%$ alcohol for skin hygiene.

Examination consisted of placing a bipolar electrode on the skin surface in each of the muscle regions of interest. The ground electrode was positioned in the elbow region ${ }^{16}$.

The procedure was performed in a closed room, without electrical or electromagnetic interference. Excess oil was removed from the muscular surface with gauze and alcohol, and the surface electrodes were then fixed. Electromyographic records were taken at rest in two moments: before and after the use of trombone. After the first electromyographic recording, the trombonist performed the song entitled "Cantiga Brasileira" by Gilberto Gagliard. The trombone used was a tenor trombone with Conn crook and bell, Kanstul valve, Edwards dual bore slide, nickel tip, and Peter Pickett 5.5 mouthpiece. After the song was finished, the volunteer was resubmitted to electromyographic evaluation.

During the two electromyographic records at rest, volunteers remained with their lips in the usual posture and their facial muscles relaxed. At the end of the recording, electromyographic tracings were expressed in RMS (Root Mean Square), selecting the windows for analysis, eliminating the initial and final seconds to avoid interference. The time spent during the entire procedure with each subject was approximately 45 minutes.

The data were categorized and allocated in a digital spreadsheet. Subsequently, the variables were descriptively and inferentially analyzed using the statistical software R (version 2.11.0). The descriptive analysis included the calculation of measures of frequency and central tendency. For inferential analysis, from the observation of data distribution normality, the paired Student's $t$ test was used to compare the mean electromyographic values before and after the use of trombone. The $5 \%$ level of significance was considered.

\section{RESULTS}

The sample consisted of 20 male trombonists with an average of 24.5 ( \pm 2.9 ) years of age.

Table 1 shows that 18 (90\%) subjects have been using this wind instrument for more than 5 years. Of the participants, $16(80 \%)$ practice trombone between 5 and 6 days a week. Regarding daily hours of practice, $40 \%$ reported having 3 hours of daily practice. All participants do not have any other professional activity besides music. 
Table 1. Musical career of trombonists

\begin{tabular}{|c|c|c|}
\hline \multirow{2}{*}{ Variable } & \multicolumn{2}{|c|}{ Total } \\
\hline & $\mathbf{n}$ & $\%$ \\
\hline \multicolumn{3}{|l|}{ Practice Time } \\
\hline 3 Years & 1 & 5.0 \\
\hline 4 Years & 1 & 5.0 \\
\hline 5 Years or more & 18 & 90.0 \\
\hline \multicolumn{3}{|l|}{ Practice Frequency } \\
\hline 3 Days & 3 & 15.0 \\
\hline 4 Days & 1 & 5,0 \\
\hline 5 Days & 5 & 25.0 \\
\hline 6 Days & 11 & 55.0 \\
\hline \multicolumn{3}{|c|}{ Daily Hours of Practice } \\
\hline 1 Hour & 2 & 10.0 \\
\hline 2 Hours & 6 & 30.0 \\
\hline 3 Hours & 8 & 40.0 \\
\hline 4 Hours or more & 4 & 20.0 \\
\hline \multicolumn{3}{|c|}{ Instrument Type (bass or tenor) } \\
\hline 1 & 5 & 25.0 \\
\hline 2 & 15 & 75.0 \\
\hline
\end{tabular}

As for their perception of signs and symptoms of oromyofunctional changes, Table 2 shows that 11 subjects $(55 \%)$ reported making muscle compensations. Of the 14 subjects who reported symptoms, 7 (35\%) mentioned fatigue, 3 (15\%) reported muscle tension, 2 reported having more than one symptom, only 1 (5\%) reported pain, and 1 (5\%) mentioned cervical weakness. Most participants stated that they play the instrument in the proper posture and that their muscles are currently more resistant. Only one musician sought health professionals to treat a problem related to orofacial myofunctional alteration.

Table 2. Perception of trombonists about signs and symptoms of myofunctional changes correlated with playing the instrument

\begin{tabular}{lcccc}
\hline \multirow{2}{*}{ Variable } & \multicolumn{2}{c}{ No } & Yes \\
\cline { 2 - 5 } & $\mathbf{N}$ & \% & $\%$ \\
\hline Muscle compensations & 9 & 45.0 & 11 & 55.0 \\
Practice beyond physical capacity & 17 & 85.0 & 3 & 15.0 \\
Symptoms & 6 & 30.0 & 14 & 70.0 \\
Proper posture & 4 & 20.0 & 16 & 80.0 \\
More resistant facial muscles & 2 & 10.0 & 18 & 90.0 \\
Search for pain/tension/fatigue treatment & 19 & 95.0 & 1 & 5.0 \\
\hline
\end{tabular}

As for posture of structures of the stomatognathic system (SS), results show a high proportion of mild changes in cheek volume (90\%) and changes in the midline (85\%), in addition to mild facial asymmetry in half of the subjects (Table 3 ). 
Table 3. Posture of the stomatognathic structures (face, cheeks, and jaw) of trombonists

\begin{tabular}{|c|c|c|}
\hline \multirow{2}{*}{ Variable } & \multicolumn{2}{|c|}{ Total } \\
\hline & $\mathbf{N}$ & $\%$ \\
\hline \multicolumn{3}{|c|}{ Face } \\
\hline \multicolumn{3}{|l|}{ Symmetry } \\
\hline Normal & 10 & 50.0 \\
\hline Mild asymmetry & 10 & 50.0 \\
\hline \multicolumn{3}{|c|}{ Proportion between facial thirds } \\
\hline Normal & 16 & 80.0 \\
\hline Slightly altered & 4 & 20.0 \\
\hline \multicolumn{3}{|l|}{ Nasolabial sulcus } \\
\hline Normal for age & 14 & 70.0 \\
\hline Sharp - Mild & 6 & 30.0 \\
\hline \multicolumn{3}{|c|}{ Appearance of cheeks } \\
\hline \multicolumn{3}{|l|}{ Volume } \\
\hline Normal & 2 & 10.0 \\
\hline Mild change & 18 & 90.0 \\
\hline \multicolumn{3}{|c|}{ Tension/Configuration } \\
\hline Normal & 19 & 95.0 \\
\hline Moderate change & 1 & 5.0 \\
\hline \multicolumn{3}{|c|}{ Mandible/Maxilla ratio } \\
\hline \multicolumn{3}{|l|}{ Vertical } \\
\hline Normal & 15 & 75.0 \\
\hline Mild change & 5 & 25.0 \\
\hline \multicolumn{3}{|l|}{ Anteroposterior } \\
\hline Normal & 14 & 70.0 \\
\hline Mild change & 6 & 30.0 \\
\hline \multicolumn{3}{|l|}{ Midline } \\
\hline Normal & 3 & 15.0 \\
\hline Mild change & 10 & 50.0 \\
\hline Moderate change & 5 & 25.0 \\
\hline Severe change & 2 & 10.0 \\
\hline
\end{tabular}

The majority of the trombonists evaluated showed normal appearance and posture of stomatognathic structures (lips, chin, tongue, hard palate). Labial commissures had a downward orientation or were asymmetric in $60 \%$ (12) of these subjects (Table 4). 
Table 4. Posture of the stomatognathic structures (lips, chin, tongue, hard palate) of trombonists

\begin{tabular}{|c|c|c|}
\hline \multirow{2}{*}{ Variable } & \multicolumn{2}{|c|}{ Total } \\
\hline & $\mathbf{N}$ & $\%$ \\
\hline \multicolumn{3}{|c|}{ Lips } \\
\hline \multicolumn{3}{|l|}{ Lip function at rest } \\
\hline Occluded & 18 & 90.0 \\
\hline Mild dysfunction & 2 & 10.0 \\
\hline \multicolumn{3}{|l|}{ Volume and configuration } \\
\hline Normal & 14 & 70.0 \\
\hline Decreased and stretched - Mild & 5 & 25.0 \\
\hline Decreased and stretched - Moderate & 1 & 5.0 \\
\hline \multicolumn{3}{|l|}{ Labial comissures } \\
\hline Normal & 8 & 40.0 \\
\hline Below the oral rhyme and/or asymmetric - Mild & 12 & 60.0 \\
\hline \multicolumn{3}{|c|}{ Mentual muscle } \\
\hline \multicolumn{3}{|l|}{ Apparent contraction - occluded lips } \\
\hline Normal & 19 & 95.0 \\
\hline Mild & 1 & 5.0 \\
\hline \multicolumn{3}{|c|}{ Tongue } \\
\hline \multicolumn{3}{|l|}{ Position/Appearance } \\
\hline Normal & 17 & 85.0 \\
\hline Clenching - Tense occlusion of teeth & 1 & 5.0 \\
\hline Tightening - With marks & 2 & 10.0 \\
\hline \multicolumn{3}{|l|}{ Appearance - Volume } \\
\hline Normal & 14 & 70.0 \\
\hline Increased and/or extended - Mild & 5 & 25.0 \\
\hline Increased and/or extended - Moderate & 1 & 5.0 \\
\hline \multicolumn{3}{|c|}{ Appearance of the hard palate } \\
\hline \multicolumn{3}{|l|}{ Width } \\
\hline Normal & 19 & 95.0 \\
\hline Mild decrease & 1 & 5.0 \\
\hline \multicolumn{3}{|l|}{ Height } \\
\hline Normal & 13 & 65.0 \\
\hline Mild increase & 6 & 30.0 \\
\hline Moderate increase & 1 & 5.0 \\
\hline
\end{tabular}

Lip mobility was sufficient in the majority of the trombonists. For laterality movements, $25 \%$ of the subjects presented insufficiency. Regarding tongue movements, some of the subjects showed insufficient protrusion, laterality, raising, and lowering. Regarding jaw mobility, the most affected ability was lowering. 
Table 5. Mobility of the stomatognathic structures of trombonists

\begin{tabular}{|c|c|c|c|c|c|c|c|c|c|c|c|c|}
\hline \multirow{2}{*}{ Performance } & \multicolumn{2}{|c|}{ Protrusion } & \multicolumn{2}{|c|}{ Retraction } & \multicolumn{2}{|c|}{ Laterality (R) } & \multicolumn{2}{|c|}{ Laterality (L) } & \multicolumn{2}{|c|}{ Raising } & \multicolumn{2}{|c|}{ Lowering } \\
\hline & $\mathrm{N}$ & $\%$ & $\mathrm{~N}$ & $\%$ & $\mathrm{~N}$ & $\%$ & $\mathrm{~N}$ & $\%$ & $\mathrm{~N}$ & $\%$ & $\mathbf{N}$ & $\%$ \\
\hline \multicolumn{13}{|l|}{ Lips } \\
\hline Normal & 19 & 95.0 & 16 & 80.0 & 15 & 75.0 & 15 & 75.5 & - & - & - & - \\
\hline Insufficient & 1 & 5.0 & 4 & 20.0 & 5 & 25.0 & 5 & 25.0 & - & - & - & - \\
\hline \multicolumn{13}{|l|}{ Tongue } \\
\hline Normal & 12 & 60.0 & 15 & 75.0 & 11 & 55.0 & 11 & 55.0 & 10 & 50.0 & 12 & 60.0 \\
\hline $\begin{array}{l}\text { Insufficient } \\
\text { Mandible }\end{array}$ & 8 & 40.0 & 5 & 25.0 & 9 & 45.0 & 9 & 45.0 & 10 & 50.0 & 8 & 40.0 \\
\hline Normal & 18 & 90.0 & - & - & 17 & 85.0 & 15 & 75.0 & 16 & 80.0 & 14 & 70.0 \\
\hline Insufficient & 2 & 10.0 & - & - & 3 & 15.0 & 5 & 25.5 & 4 & 20.0 & 6 & 30.0 \\
\hline
\end{tabular}

Captions: $R=$ right; $L=$ left.

Nineteen subjects (95\%) were able to inflate and lateralize the air, and all of them moved their cheeks normally as these are movements trained daily when playing the trombone.

Table 6. Mobility of the cheeks of trombonists

\begin{tabular}{lcccccccc}
\hline \multirow{2}{*}{ Performance } & \multicolumn{2}{c}{ Inflating } & \multicolumn{2}{c}{ Deflating } & \multicolumn{2}{c}{ Retracting } & \multicolumn{2}{c}{ Lateralizing } \\
\cline { 2 - 9 } & $\mathbf{N}$ & $\%$ & $\mathbf{N}$ & $\%$ & $\mathbf{N}$ & $\%$ & $\mathbf{N}$ & $\%$ \\
\hline Cheeks & & & & & & & & \\
Normal & 19 & 95.0 & 20 & 100 & 20 & 100 & 19 & 95.0 \\
Insufficient & 1 & 5.0 & 0 & 0.0 & 0 & 0.0 & 1 & 5.0 \\
\hline
\end{tabular}

Regarding breathing, 55\% of those assessed had oronasal breathing, divided into three degrees. Regarding chewing, only one subject did not perform the function normally, as he was unable to perform the solid cake task. In swallowing, $15 \%(n=3)$ of the subjects contracted the orbicularis oris muscle. 
Table 7. Stomatognathic functions in trombonists

\begin{tabular}{|c|c|c|}
\hline \multirow{2}{*}{ Variable } & \multicolumn{2}{|c|}{ Total } \\
\hline & $\mathbf{N}$ & $\%$ \\
\hline \multicolumn{3}{|c|}{ Breathing } \\
\hline Nasal & 9 & 45.0 \\
\hline \multicolumn{3}{|l|}{ Oronasal } \\
\hline Mild & 5 & 25.0 \\
\hline Moderate & 5 & 25.0 \\
\hline Severe & 1 & 5.0 \\
\hline \multicolumn{3}{|c|}{ Deglutition } \\
\hline \multicolumn{3}{|l|}{ Lips } \\
\hline Sealed & 17 & 85.0 \\
\hline Sealed with contraction/interposition & 3 & 15.0 \\
\hline \multicolumn{3}{|l|}{ Tongue } \\
\hline Contained in the oral cavity & 20 & 100 \\
\hline \multicolumn{3}{|l|}{ Deglutition - Efficiency } \\
\hline No repetition for the same cake & 15 & 75.0 \\
\hline One repetition & 3 & 15.0 \\
\hline Multiple swallows & 2 & 10.0 \\
\hline \multicolumn{3}{|l|}{ Chewing } \\
\hline Normal & 19 & 95.0 \\
\hline Does not chew & 1 & 5.0 \\
\hline
\end{tabular}

Electromyographic values decreased for the upper and lower lips after the instrument was played, with a statistically significant difference only for the lower orbicularis oris muscle.

Table 8. Comparison of the mean values of the electromyographic analysis of the orbicularis oris muscle of trombonists before and after playing the instrument

\begin{tabular}{|c|c|c|c|c|c|c|}
\hline \multirow{2}{*}{ Variable } & \multicolumn{2}{|c|}{ Before playing } & \multicolumn{2}{|c|}{ After playing } & \multirow{2}{*}{ p-value } & \multirow{2}{*}{ Difference } \\
\hline & Mean & SD & Mean & SD & & \\
\hline Upper orbicularis oris mucle & 3.54 & 1.0 & 2.95 & 1.9 & 0.07 & NO \\
\hline Lower orbicularis oris muscle & 6.95 & 8.1 & 5.08 & 6.3 & 0.04 & YES \\
\hline
\end{tabular}

Paired Student's t; ${ }^{*} p<0.05$

\section{DISCUSSION}

The present study identified clinical and selfreported oromyofunctional changes in trombonists, as well as a reduction in the electrical activity of the lower orbicularis oris muscle in these individuals.

The fact that the subjects are university students and work exclusively with music facilitated the analysis of the available variables. The male gender was chosen so as to avoid bias that could interfere with the results due to the intrinsic characteristics of each gender.
There is a lack of awareness of the extent to which some behaviors, such as the practice of a wind instrument, can harm health ${ }^{7,20}$. The trombonists analyzed in the present study practice their instrument at least six days a week for more than two hours a day. Previous research shows that the amount of practice/ study time with an instrument may lead to overuse and wrong use of the stomatognathic system (SS) ${ }^{5-8}$.

The studied subjects claimed not to use more than their physical capacity in playing the instrument. However, reports in the literature demonstrate an obstinate search for ideal performance, often leading 
the trombonist to exaggerated physical effort ${ }^{9}$. The present study showed that trombonists need to make compensations in facial and cervical muscles. This reveals that some of these individuals may present anatomical characteristics that do not facilitate the practice of the instrument. They thus tend to perform these compensations, which can negatively affect the orofacial complex ${ }^{4}$. This points to the need for oral health professionals to provide information about the possible effects that may be caused by playing wind instruments, which could minimize secondary symptoms that can affect the $\mathrm{SS}^{21}$.

Instrumentalists tend to adapt the instrument to their physical condition at the expense of physiological movement. In general, the posture when playing the instrument is asymmetric and not ergonomic'. However, this statement differs from the feeling of the interviewed subjects, who claimed to play the trombone in an appropriate posture. A possible explanation for this finding would be the lack of knowledge on the part of the instrumentalists of what would be a balanced posture, which, in turn, would favor the appearance of other conditions and structural complications.

The instrumentalists reported orofacial symptoms associated with trombone playing. Fatigue is the most common symptom, followed by tension in the orofacial region. Musicians in general, including musicians who play wind instruments, report mostly pain ${ }^{9,22}$ but also fatigue as a symptom ${ }^{23,24}$.

The appearance of the lips, chin, tongue, and hard palate of the trombonists is normal in comparison to that of other populations. The anatomical structures most affected by the practice of wind instruments are the orofacial structures and the spine ${ }^{25}$. These observations characterize the appearance and postural condition of the stomatognathic structures of the volunteers in this research. However, these structures may not correlate directly with the performance of the wind instrument ${ }^{26}$.

To date, there are no studies addressing the muscle condition of this target population. The electrical activity of the orbicularis oris muscle decreased, with a statistically significant difference for the lower orbicularis oris muscle. The results, thus, showed that the upper and lower segments of the orbicularis oris muscle work independently, as already demonstrated in another study ${ }^{27}$.

Muscle fatigue is characterized as the inability of the musculature to maintain high levels of strength over time ${ }^{28}$. A study analyzing the electrical activity of the extrinsic muscles of the larynx in subjects with and without dysphonia concluded that the muscle groups studied had lower electrical activity. This may indicate either a reduction in muscle resistance or the possibility of fatigue in the studied musculature, possibly due to the excessive use of these muscles ${ }^{29}$. Fatigue depends on the duration, type, and intensity of the exercise. Therefore, the decreased electrical activity of muscles in the present study probably correlates with playing the wind instrument. Trombone playing requires a greater effort of the orbicularis oris muscles in a short period of time, which makes it difficult to perform the basic functions of these muscles, causing the need for adaptations.

Research suggests that the orbicularis oris muscle is more prone to fatigue in certain professions, while in others it remains unchanged ${ }^{30}$. Therefore, the use of wind musical instruments should be a matter of particular attention, as they can be a potential source of pathological changes in the structures and functions of the stomatognathic system. This poses an important challenge for the prevention and treatment of orofacial complications among these individuals, as these complications can lead to chronic sequelae preventing musical practice, with inherent professional repercussions ${ }^{4}$.

\section{CONCLUSION}

Trombonists have clinical and self-reported oromyofunctional changes. The electrical activity of the lower orbicularis oris muscle decreases and that of the upper orbicularis oris muscle does not change after playing the trombone. The results suggest an imbalance of the stomatognathic system in this population

\section{REFERENCES}

1. Douglas $\mathrm{CR}$. Fisiologia aplicada à fonoaudiologia. 2. ed. Rio de Janeiro: Guanabara-Koogan, 2006.

2. Pernambuco LA, Cunha RA, Lins $O$, Leão JC, Silva HJ. A eletromiografia de superfície nos periódicos nacionais em Fonoaudiologia. Rev. CEFAC. 2010;12(4):685-92

3. Silva HJ, Cunha DA. O sistema estomatognático: anatomofisiologia e desenvolvimento. São José dos Campos: Pulso Editorial; 2011.

4. Frias-Bulhosa J. Impactos oro-faciais associados à utilização de instrumentos musicais. Rev. Portuguesa de Estomatol Med Dent Cir Maxilofacial. 2012;53(2):108-16. 
5. Zimmers P, Gobetti J. Head and neck lesions commonly found in musicians. Journal Am Dent Assoc. 1994;125(11):1487-96.

6. Yeo D, Pham T, Baker J, Porter S. Specific orofacial problems experienced by musicians. Aust Dent $\mathrm{J}$. 2002;47:(1):2-11.

7. Gansenzer E, Parncutt R. How do musicians deal with their medical problems? $9^{\text {th }}$ Internacional Coference on Music Perception and Cognition. Alma Mater Studiorum Bologna University. 2006.

8. Steimetz A, Ridder P, Methfessel G, Muche B. Professional musicians with craniomandibular dysfunctions treated with oral splints. Cranio. 2009;27(4):221-30.

9. Frank A, Muhlen CV. Queixas musculoesqueléticas em músicos: prevalência e fatores de risco. Rev. Bras. Reumatol. 2007;47(3):188-96.

10. Bianchini EMG. Avaliação fonoaudiológica da motricidade oral: distúrbios miofuncionais orofaciais ou situações adaptativas. Rev. Dent. Press Ortodon. Ortop. Facial. 2000;6(3):73-82.

11. Marchesan IQ. Frênulo lingual: proposta de avaliação quantitativa. Rev. CEFAC. 2004;6(3):288-93.

12. Junqueira $P$. Avaliação miofuncional. In: Marchesan IQ (org). Fundamentos em fonoaudiologia: aspectos clínicos da motricidade oral. Rio de Janeiro: Guanabara Koogan; 2005.p.19-27.

13. Genaro KF, Berretin F, Rehder MIBC, Marchesan IQ. Avaliação Miofuncional Orofacial - Protocolo MBGR. Rev. CEFAC. 2009;11(2):237-55.

14. Trindade IEK, Genaro KF, Yamashita RP, Miguel HC, Fukushiro AP. Proposta de classificação da função velofaríngea na avaliação perceptivo-auditiva da fala. Pró-Fono R Atual. Científ. 2005;17(2):259-62.

15. Folha GA. Ampliação das escalas numéricas do Protocolo Avaliação Miofuncional Orofacial (AMIOFE-A), validação e confiabilidade [dissertação]. Ribeirao Preto (SP): Universidade de São Paulo, Faculdade de Medicina de Ribeirão Preto; 2010.

16. Silva HJ. Protocolos de Eletromiografia de Superfície em Fonoaudiologia. Pró-Fono: Barueri, 2013.

17. Rahal A, Pierotti S. Eletromiografia e cefalometria na Fonoaudiologia. In: Ferreira LP, Befi-Lopes DM, Limongi SCO (orgs). Tratado de fonoaudiologia. São Paulo: Roca; 2004. p. 237-53.
18. Tomé MC, Marchiori SC. Análise eletromiográfica dos músculos orbiculares superior e inferior da boca em crianças respiradoras nasais e bucais durante a emissão de sílabas. Pró-Fono R Atual. Cientif. 1999;11(1):1-7.

19. Lakatos EM, Marconi MA. Fundamento de metodologia científica. 4a ed. São Paulo: Atlas; 2003.

20. Freitas DCV, Marques K. Prevalência da disfunção temporomandibular em violinistas e violistas da Orquestra Petrobras Sinfônica. Rev Eletrônica Novo Enfoque. 2010;10:58-67.

21. Iranzo M, Pérez-Soriano $P$, Camacho $C$, Belloch $S$, Cortell-Tormo J. Playing-related musculoskeletal disorders in woodwind, brass and percussion players: a review. J. Hum. Sport Exerc. 2010;5(1):94-100.

22. Lacerda F, Barbosa C, Pereira S, Manso MC. Estudo de prevalência das disfunções temporomandibulares em estudantes de instrumento de Sopro. Rev Port Estomatol Med Dent Cir Maxilofac. 2015;56(1):25-33.

23. Chesky K, Devroop K, Ford J. Medical problems of brass instrumentalists: prevalence rates for trumpet, trombone, French horn, and low brass. Med Probl Perform Artist. 2002;17(2):93-8.

24. Steimetz A, Stang A, Kornhuber $M$, Röllinghroff M, Delank KS, Altenmüller E. From embouchure problems to dystonia? A survey of self-reported embouchure disordersin 585 professional orchestra brass players. Int Arch Occup Environ Health. 2014;87(7):783-92.

25. Lederman RJ. Neuromuscular and musculoskeletal problems in instrumental musicians. Muscle \& Nerve. 2003;27(5):549-61.

26. Siqueira VCV, Sousa MA, Bérzin F, Casarini CAS. Análise eletromiográfica do músculo orbicular da boca em jovens com Classe II, 1a divisão, e jovens com oclusão normal. Dental Press J Orthod. 2011;16(5):54-61.

27. Zilli AS. Estudo eletromiográfico dos músculos orbiculares da boca, segmentos superior e inferior (região medial), em jovens com maloclusão Classe I de Angle [dissertação]. Piracicaba (SP): Universidade Estadual de Campinas; 1994.

28. Santos MG, Dezan VH, Sarraf TA. Bases metabólicas da fadiga muscular aguda. Rev Bras $\mathrm{C}$ Mov. 2003;11(1):7-12. 
29. Balata PMM, Silva HJ, Pernambuco LA, Amorim GO, Braga RS, Silva EGFS et al. Electrical activity of extrinsic laryngeal muscles in subjects with and without dysphonia. J Voice. 2015;29(1):129.e9-129. e17.

30. Busanello-Stella AR, Silva AMT, Corrêa E. Research on fatigue in facial and jaw muscles: review of the literature. Rev. CEFAC. 2014;16(5):1627-38. 


\section{ANNEX A}

\section{Musical career with the instrument}

Name:

Email

DN: Age:

Date: Tel:

1. How long (years) have you been playing the trombone?
$1 y$
2y $\quad 3 y$
4y
5y or more

2. How many days a week do you usually practice the instrument?
1 day
3 days
5 days
7 days
2 days
4 days 6 days

3. How many hours a day do you usually practice the instrument?

$1 \mathrm{~h} \quad 3 \mathrm{~h}$

$2 \mathrm{~h} \quad 4 \mathrm{~h}$ or more

4. What brand is your instrument?

5. Your trombone is a:
(1) Bass trombone
(2) Tenor trombone

6. Do you feel any of these symptoms on your face?
(1) Pain
(3) Fatigue
(5) Cervical (neck) weakness
(2) Tension
(4) Facial weakness

7. Do you think your muscles need to make many compensations for you to play your instrument?
(1) YES
(2) NO

8. Do you think you go beyond your physical capacity in playing your instrument?

(1) YES

(2) NO

9. Do you consider your posture adequate when playing the trombone?
(1) YES
(2) NO

10. Do you work with anything other than music? If so, please specify.
(1) YES:
(2) NO

11. Do you think your facial muscles are currently more resistant?
(1) YES
(2) NO

12. Is there anything not mentioned above that you want to talk about in relation to your health and the instrument you play?
(1) YES
(2) NO

13. Are you very anxious before performing on a trombone?
(1) YES
(2) NO

14. Have you ever sought a health professional to treat pain, tension, or fatigue?
(1) YES
(2) NO 